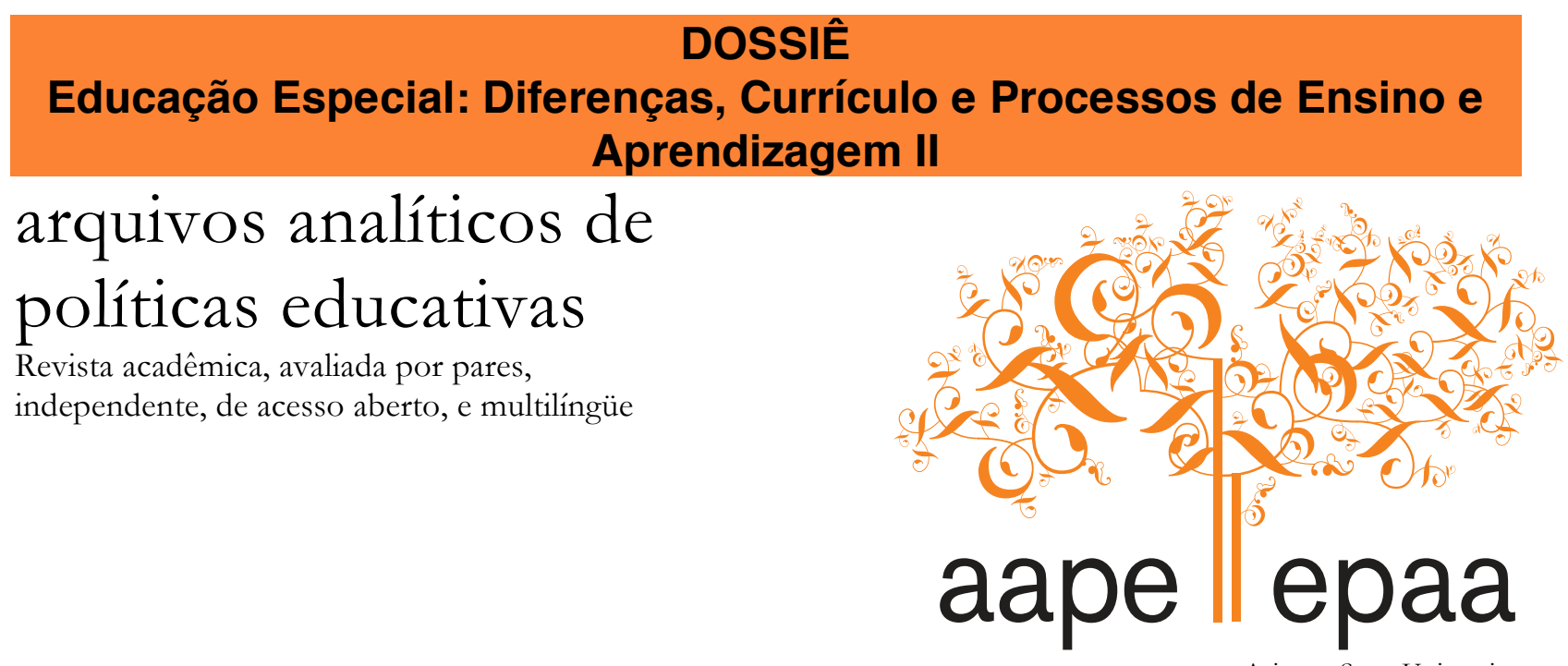

Arizona State University

\title{
Uso de Sistemas Gráficos na Rotina da Sala de Aula Regular com Aluno com Deficiência
}

\author{
Débora Deliberato \\ UNESP - Universidade Estadual Paulista "Julio de Mesquita" \\ Brasil \\ \& \\ Leila Regina d'Oliveira Paula Nunes \\ UERJ - Universidade do Estado do Rio de Janeiro \\ Brasil
}

Citação: Deliberato, D., \& Nunes, L. R. d'O. P. (2015). Uso de sistemas gráficos na rotina da sala de aula regular com aluno com deficiência. Arquivos Analíticos de Politicas Educativas, 23(34). Dossiê Educação Especial: Diferenças, Currículo e Processos de Ensino e Aprendizagem II. Editoras convidadas: Márcia Denise Pletsch \& Geovana Mendonça Lunardi Mendes. http://dx.doi.org/10.14507/epaa.v23.1655

Resumo: Adequar o contexto escolar para a diversidade de alunos é uma meta importante, mas é um desafio frente à diversidade de alunos com deficiência. O objetivo deste trabalho foi descrever o uso de sistemas gráficos na rotina de uma sala da educação infantil por meio de um trabalho colaborativo. Participaram do estudo uma professora, 22 alunos de uma sala de aula da educação infantil de uma escola de uma cidade de grande porte na região sudeste do Brasil, uma mãe de uma criança com deficiência e um professor de apoio. Foi realizado um programa de ações colaborativas entre a pesquisadora, professora e os alunos da sala para inserir o sistema gráfico na rotina de atividades pedagógicas durante quatro meses. As atividades foram registradas por meio do diário de campo, filmagens e gravação das entrevistas realizadas por meio do protocolo. Os resultados obtidos 
por meio da análise de temas mostraram que as crianças usaram o sistema gráfico na rotina de atividades, o sistema gráfico auxiliou as crianças na leitura das palavras, o professor inseriu o sstema gráfico a partir da mediação da pesquisadora e, a rotina das atividades pedagógicas planejada pelo professor facilitou a inserção do sistema gráfico na sala de aula entre os alunos. O trabalho reforçou a necessidade de um programa de capacitação dos interlocutores da escola para incluir o aluno com deficiência.

Palavras-chave: educação especial; inclusão; comunicação ampliada e alternativa; formação de professores

\section{Use of Graphic Systems in the Routine of Regular Classroom With a Disabled Student}

Abstract: The school environment adapted to the diversity of students is an important goal, but it is a challenge when it comes to the diversity of students with disabilities. The aim of this study was to describe the use of graphics systems in the routine of a preschool classroom through a collaborative program. The study included a teacher, 22 children of a preschool classroom in a school located in a large city in southeastern of Brazil, the mother of a child with disabilities and a special education teacher. A program of collaborative action was carried out among the researcher, the teacher and the students to insert the graphic system in the routine of educational activities for four months. The activities were recorded through a log book, filming and digital recording of interviews. The results obtained from the analysis of the themes identified that the children used the graphic system in the routine of the school tasks, the graphic system helped children in reading the words, the teacher facilitated the insertion of the graphic system from the mediation of the researcher, and the routine of educational activities planned by the teacher facilitated the insertion of the graphic system in the classroom among the students. The study reinforced the need for a training program aimed at school interlocutors to include students with disabilities.

Keywords: special education; inclusion; augmentative and alternative communication; teacher training

\section{E1 Uso de Sistemas Gráficos en la Rutina de la Clase Regular Con un Estudiante Discapacitado}

Resumen: El ambiente escolar adaptado a la diversidad de los estudiantes es una meta importante, pero es un reto cuando se trata de la diversidad de los estudiantes con discapacidades. El objetivo de este estudio fue describir el uso de sistemas gráficos en la rutina de una clase de alumnos preescolares a través de un programa de colaboración. El estudio incluyó a un maestro, a 22 niños de una clase de preescolar en una escuela de una gran ciudad en el sureste de Brasil, la madre de un niño con discapacidad, y un maestro de educación especial. Un programa de acción de colaboración fue realizado entre el investigador, el profesor y los estudiantes para insertar el sistema gráfico en la rutina de actividades educativas durante cuatro meses. Las actividades fueron registradas a través de un libro de registro, filmación y grabación digital de entrevistas. Los resultados obtenidos a partir del análisis de los temas identificaron que los niños usan el sistema gráfico en la rutina de las tareas de la escuela, el sistema gráfico ayudó a los niños en la lectura de las palabras, el maestro facilitó la inserción del sistema gráfico a partir de la mediación de la investigadora, y la rutina de las actividades educativas programadas por el profesor facilitó la inserción del sistema gráfico en la clase entre los estudiantes. El estudio ha reforzado la necesidad de un programa de formación dirigido a los interlocutores de la escuela para incluir a los estudiantes con discapacidades.

Palabras-clave: educación especial; inclusión; comunicación aumentativa y alternativa; formación del profesorado 


\section{Introdução}

Por volta da década de 1960, pesquisadores já discutiam que os sistemas de comunicação ampliada e alternativa (CAA) ${ }^{1}$ poderiam transformar-se em suportes, alternativas ou até mesmo substituírem a linguagem falada, para sustentar e favorecer a aquisição e desenvolvimento da linguagem de crianças com desordens motoras, distúrbios de linguagem, autismo e distúrbios de aprendizagem (Nunes, Quiterio, Walter, Schirmer, \& Braun, 2011; Von Tetzchner \& Grove, 2003). Os autores ainda enfatizaram que, embora tais sistemas pudessem promover o acesso aos diferentes significados de ideias compartilhadas e construídas, seria possível identificar dificuldades na sua utilização. As barreiras poderiam estar relacionadas a como modificar ou ampliar o entendimento dos usuários de CAA diante de um sistema de comunicação nem sempre compartilhado pela comunidade linguística, e como trabalhar as atitudes das pessoas frente aos valores oferecidos à capacidade de falar frente às formas alternativas de comunicação (Delgado, 2011; Deliberato, 2013).

Os indivíduos sem fala articulada encontram interlocutores que sejam usuários competentes desses sistemas, os quais que possam funcionar como modelos nas situações de rotina de vida. As trocas comunicativas muitas vezes ocorrem durante os processos de intervenção terapêutica ou mesmo em situações educacionais programadas (Alves, 2006; Binger \& Light, 2007; Light \& McNaughton, 2013; Sameshima, 2006).

O sucesso do início das possibilidades expressivas, ou seja, a linguagem expressiva está dependente das atitudes e conhecimentos dos profissionais atuantes com as pessoas com deficiência não falantes. As crianças e jovens podem desenvolver com seus familiares diferentes formas de comunicação, tais como os gestos, direcionamento do olhar, vocalizações e expressões faciais, mas dependem de programas de intervenções para que sistemas linguísticos possam ser aprendidos.

A intervenção com a comunicação ampliada e alternativa precoce pode ser crítica para o desenvolvimento da linguagem e, assim, favorecer o desenvolvimento da comunicação e das habilidades sociais. Crianças e jovens com deficiência poderiam ser beneficiados com os programas de intervenção precoce, proporcionando mudanças de atividade comunicativa de passiva para ativa (De Coste, 1997; Quiterio \& Brando, 2011).

A literatura abordou a relevância dos sistemas de comunicação ampliada e alternativa em propiciar não só uma variedade de funções pragmáticas, mas que desenvolvam um potencial para a aquisição e desenvolvimento da linguagem e facilitem as competências subjacentes à compreensão e produção da linguagem gerada (Light, 2003; Light \& McNaughton, 2013; Mirenda \& Locke, 1989).

Gulens, Kerbel e Nobel (2006) consideraram a importância de os profissionais estarem atentos aos tipos de estratégias necessárias no processo de intervenção direcionados aos indivíduos com severa complexidade de comunicação. Os mesmos autores enfatizaram que, no momento de organizar e programar as estratégias, os profissionais deveriam identificar e reconhecer o nível de habilidades comunicativas já usadas por pessoas com deficiência. Dessa forma, os programas de intervenção poderiam contribuir na ampliação das habilidades de comunicação de forma mais funcional (Delagracia, 2007; Deliberato, Manzini, \& Guarda, 2004; Fernandes, 2001; Paula, 2007).

Os programas de intervenção poderiam sustentar o desenvolvimento da competência linguística das crianças e jovens com severa dificuldade de comunicação. A pessoa com deficiência necessita ter o domínio da língua natural do seu meio, mas terá que aprender um sistema de representação que lhe possa garantir a qualidade de novos aprendizados e, com isso, propiciar o acesso à interação e comunicação com diferentes pessoas (Beukelman \& Mirenda, 2007; Deliberato, 2013; Nunes et al., 2011).

\footnotetext{
${ }^{1}$ No Brasil não há sistematização da tradução da terminologia Augmentative and Alternativa Communication. É possível
} 
O desafio para o desenvolvimento da competência linguística é maior para as crianças que usam CAA, pelo menos por três razões: a) existe uma diferença significativa entre o input de linguagem recebida pelos indivíduos que empregam CAA e o output utilizado por eles; b) a comunicação por meio da CAA é tipicamente multimodal, combinando vários códigos linguísticos para expressar significados (por exemplo, sinais manuais, gestos convencionais, fotos, símbolos gráficos); e c) muitos sistemas de CAA não têm vínculo com uma linguagem natural, faltando aspectos fonológicos, semânticos, sintáticos e ou pragmáticos (Binger \& Light, 2007; Light, 2003; Light \& McNaughton, 2013).

A literatura da área tem discutido que é um desafio sistematizar programas de intervenção baseados em sistemas de CAA, frente à diversidade de pessoas com deficiências que necessitam de instrumentos para a comunicação. A mesma literatura também tem ponderado que é um desafio maior inserir tais sistemas nos diferentes ambientes para ampliar as possibilidades comunicativas e garantir meios para desenvolver interlocutores competentes no uso dos sistemas de representação não empregados na comunidade (Deliberato, 2013, 2011; Schirmer \& Nunes, 2011).

Discutir a respeito dos sistemas ampliados e alternativos de comunicação é pensar não somente nas habilidades e necessidades das pessoas com deficiências, mas, seria necessário: a) instrumentalizar os interlocutores, b) adequar os ambientes, c) adaptar as atividades e tarefas utilizadas por crianças e jovens com deficiência não falante na rotina escolar e familiar.

A preocupação de profissionais e pesquisadores em garantir a permanência de alunos com deficiência no ensino regular vem ampliando ações teóricas e práticas, tanto na formação de professores, quanto na implementação de programas envolvendo parcerias entre profissionais de diferentes áreas (Deliberato, 2009, 2013; Deliberato \& Manzini, 2006; Nunes et al., 2011; Schirmer, 2011).

No que se refere à área de comunicação ampliada e alternativa, pesquisas demonstraram que o uso de recursos e estratégias envolvendo os sistemas gráficos favorece não só as habilidades comunicativas, mas também viabiliza a participação do aluno com deficiência não falante nas atividades pedagógicas programadas pelo professor (Deliberato, 2009; Rocha \& Deliberato, 2012).

Segundo Brekke e von Tetzchner (2003) e Soto e von Tetzchner (2003) pensar a respeito da inclusão plena significa admitir tanto que os alunos com deficiência sem linguagem falada têm competência em utilizar a comunicação ampliada e alternativa, quanto que os recursos e instrumentos deveriam ser utilizados além da função comunicativa, ou seja, deveriam estar disponíveis na rotina de atividades da sala de aula dos alunos (Sameshima, 2011).

A escola poderia ser um ambiente importante para favorecer o suporte necessário para os alunos com deficiência no uso de tais sistemas (Deliberato \& Manzini, 2006; Von Teztchner, Brekke, Sjothun, \& Grindheim, 2005). Na verdade, a escola tem dois desafios: garantir o suporte para as habilidades comunicativas dos alunos com deficiência não falantes e garantir a participação do mesmo aluno, nas atividades pedagógicas previstas no planejamento curricular.

Adequar o contexto escolar para a diversidade de alunos é uma meta importante, mas é um desafio frente à diversidade de alunos com deficiência. A literatura tem discutido a necessidade de capacitar o professor no uso dos diferentes recursos da tecnologia assistiva (Schirmer, 2011).

A definição do termo tecnologia assistiva é abrangente, envolve diferentes conhecimentos científicos para que o seu uso venha a contemplar as diferentes necessidades da pessoa com deficiência, proporcionando qualidade de vida (WISE, 2012).

Cabe lembrar que na legislação brasileira o termo Ajudas Técnicas aparece como sinônimo de tecnologia assistiva e foi descrito no artigo VII do decreto 5.296 de 20 de dezembro de 2004 que regulamentou a Política Nacional para a Integração da Pessoa com Deficiência. O termo se refere aos produtos, instrumentos, equipamentos ou tecnologia adaptada ou especialmente projetada para 
melhorar a funcionalidade da pessoa com deficiência ou com mobilidade reduzida, favorecendo a autonomia pessoal, total ou assistida (Brasil, 2004).

O Comitê de Ajudas Técnicas (CAT) foi criado pela Secretaria Especial dos Direitos Humanos da Presidência da República (SEDH/PR) e composto por um grupo de especialistas brasileiros e representantes de órgãos governamentais. O Comitê de Ajudas Técnicas modificou a definição proposta por Brasil (2004) e aprovou o seguinte conceito de tecnologia assistiva:

Tecnologia assistiva é uma área de conhecimento de característica interdisciplinar, que engloba produtos, recursos, metodologias, estratégias, práticas e serviços que objetivam promover a funcionalidade, relacionada à atividade e participação, de pessoas com deficiência, incapacidades ou mobilidade reduzida, visando sua autonomia, independência, qualidade de vida e inclusão social. (Cat, 2007)

Neste ontexto, o professor da sala de aula regular e os demais alunos deveriam ser capacitados no uso de recursos e estratégias adaptadas, para participar nas tarefas pedagógicas em conjunto com a criança com deficiência. A área da comunicação ampliada e alternativa tem sido um instrumento para o aprendizado da criança com deficiência e a literatura discutiu a sua inserção na escola por meio do trabalho colaborativo (Deliberato, 2013; Rocha, 2013).

A proposta dos trabalhos colaborativos consiste em levar o trabalho de diferentes especialistas para o contexto escolar. Este modelo de atuação visa contribuir com estratégias de intervenção a partir de problemas vivenciados pelos professores na escola. Os resultados deste trabalho devem favorecer a construção de possibilidades que potencializem o trabalho do educador e atendam às necessidades do aluno com deficiências. O papel do especialista é auxiliar o professor a construir estratégias e identificar as habilidades de seus alunos para que possam, de forma efetiva, desenvolver-se academicamente. A colaboração é um modelo de atuação proposto para elaborar e implementar um plano de intervenção que deve ser pensado e apoiado por todos os que estão envolvidos no processo (Machado, Bello, \& Almeida, 2012; Mendes, 2008).

O pressuposto deste modelo é o de que cabe ao pesquisador auxiliar o professor a entender melhor a prática do ensino, não apenas participando e levando inovações, mas contribuindo para reconstruir os saberes no contexto escolar e sensibilizar o professor para a necessidade de sua formação permanente (Capellini \& Mendes, 2007).

O trabalho colaborativo na escola tem também o propósito de solucionar problemas do contexto escolar e diminuir a necessidade de encaminhamentos externos para especialistas de diferentes áreas, promovendo desta forma um trabalho intersetorial. Os profissionais especializados passam a reconhecer a necessidade de oferecer apoio aos profissionais da escola tornando-se nesta perspectiva parceiros, realizando um trabalho conjunto e colaborador, através do compartilhamento de conhecimentos para a solução de problemas no contexto escolar (Machado, Bello, \& Almeida, 2012).

Considerando estas questões foi objetivo deste estudo descrever a inserção de sistemas gráficos na rotina de uma sala da educação infantil por meio de um trabalho colaborativo da pesquisadora com a professora.

\section{Método}

Este estudo faz parte de uma pesquisa maior Tecnologias de comunicaşão alternativa: recursos e procedimentos para alunos com deficiência na educação infantil com aprovação do Comitê de Ética (parecer $\mathrm{n}^{\circ}$. 0446/2012). O termo de Esclarecimento Livre e Esclarecido foi assinado pelos participantes e pelos responsáveis dos mesmos. A escola selecionada para este estudo foi indicada por uma Instituição especializada nos acompanhamentos dos alunos com deficiência no ensino regular de 
uma cidade de grande porte na região sudeste do Brasil. O critério de seleção da sala de aula da escola indicada foi a falta de experiência da escola com alunos com deficiência na educação infantil.

Participaram do estudo uma professora com 45 anos de idade, os 22 alunos de uma sala de aula da educação infantil de uma escola da cidade do Rio de Janeiro, uma professora do Atendimento Educacional Especializado (AEE) e a mãe de Ana, ${ }^{2}$ uma criança com deficiência de seis anos e quatro meses. As atividades foram realizadas na própria sala de aula.

O alunado dessa sala era composto por: 17 meninas e cinco meninos com a idade variando entre quatro e seis anos de idade. Segundo o relato da professora, a sala incluía alunos que frequentavam pela primeira vez a escola e outros que se mostravam capazes de reconhecer o nome, letras, números e estabelecendo suas hipóteses para a escrita. A professora também descreveu que além de Ana, havia alunos com transtornos de comportamento, necessitando de auxílio de profissionais especialistas. De acordo com as informações relatadas pela mãe de Ana e segundo as observações realizadas em sala de aula pela pesquisadora, a menina, não conseguia entender a rotina de sala de aula, não interagia com as outras crianças ou mesmo com a professora, sem, contudo, apresentar um diagnóstico definido. Permanecia por pouco tempo nas tarefas, mesmo quando direcionadas a ela, emitia sons sem intencionalidade, mas algumas vezes oralizava sons finais de palavras sem entretanto direcioná-las a um determinado interlocutor. O comportamento geral da criança era disperso: saía várias vezes da sala de aula e demandava do apoio da mãe ou da professora da sala de recurso multifuncional para retornar para a sala de aula. No início das observações, Ana realizava atividades fora do contexto de sala de aula e conseguia permanecer em alguma tarefa quando a professora do atendimento educacional especializado estava presente. A estrutura física da sala era composta por oito mesas para acomodar quatro crianças em cada uma nas atividades envolvendo tarefas direcionadas, como uso de pintura, escrita, entre outras. Essas mesas ficavam próximas à mesa da professora e ao lado da parede perto do banheiro. Havia ainda um espaço próximo ao quadro negro destinado à disposição de todos os alunos em círculo para desenvolver as atividades iniciais da rotina de chegada na sala de aula, a chamada, a realização do calendário coletivo e individual e ao final da aula para a explicação das tarefas de casa e demais atividades livres. A figura 1, a seguir, ilustra a disposição da sala de aula:

\footnotetext{
${ }^{2}$ Nome fictício.
} 


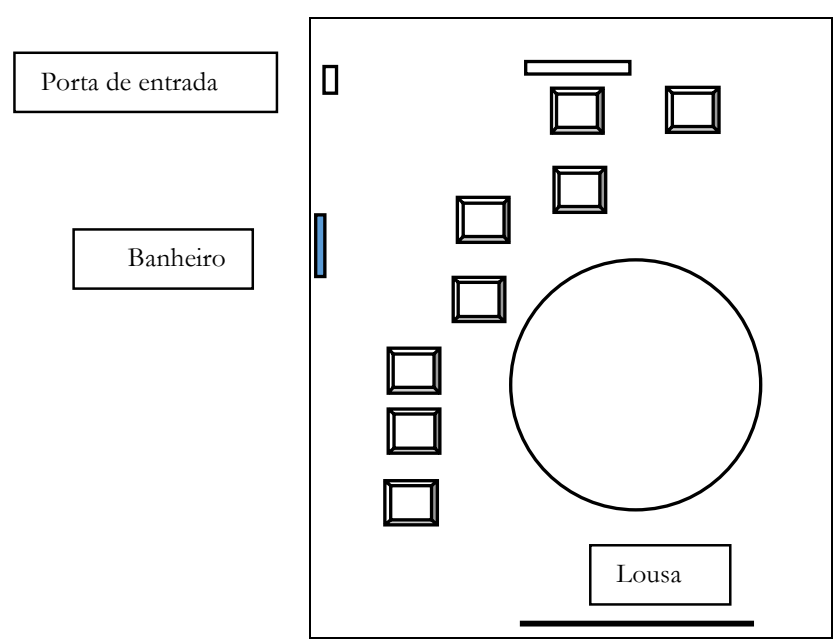

Figura 1. Esquema da disposição das cadeiras e círculo da sala de aula Fonte: produção do primeiro autor

Para a coleta de informações foram utilizados os seguintes instrumentos: Protocolo para avaliação de habilidades comunicativa para alunos não falantes em situação familiar (Delagracia, 2007) e o protocolo para avaliação de habilidades comunicativa para alunos não falantes em situação escolar (Paula, 2007). Além dos protocolos, foram conduzidos os registros da observação da rotina de sala de aula por meio do diário de campo (Falkembach, 1987; Fonseca, 1999) e as filmagens nas atividades envolvendo a criança com deficiência. As atividades previstas no programa selecionado foram feitas por meio do uso de materiais concretos (objetos), fotos, imagens pictográficas do sistema de comunicação Picture Communication Symbols (PCS) (Mayer-Johnson, 2004).

\section{Organização da Coleta de Informações}

As atividades planejadas e organizadas foram realizadas de acordo com o modelo do programa de atuação nas escolas proposto por Deliberato $(2009,2011,2013)$, durante um período de quatro meses.

O quadro 1, a seguir, descreve a organização do programa realizado e os instrumentos de coleta das informações:

Quadro 1

Descrição das Atividades, Tempo de Observação e Instrumentos de Registro

\begin{tabular}{|l|l|l|l|l|}
\hline Dia & \multicolumn{1}{|c|}{ Atividades } & $\begin{array}{c}\text { Tempo de } \\
\text { observação }\end{array}$ & $\begin{array}{c}\text { Instrumento } \\
\text { de registro }\end{array}$ & $\begin{array}{c}\text { Etapas do } \\
\text { programa }\end{array}$ \\
\hline $22 / 08 / 2013$ & Contato com as instituições e escola & & & Registro \\
contínuo & $\begin{array}{l}\text { Autorização da família, observação da sala } \\
\text { com a professora da sala de recurso. }\end{array}$ & Etapa 1 \\
\hline $\begin{array}{l}\text { Período para a Prefeitura Municipal do Rio de Janeiro e Coordenadoria Regional de Educação } \\
\text { (CRE) autorizar a realização do projeto }\end{array}$ & \\
\hline
\end{tabular}




\section{Quadro 1}

Descrição das Atividades, Tempo de Observação e Instrumentos de Registro

\begin{tabular}{|c|c|c|c|c|}
\hline $17 / 09 / 2013$ & $\begin{array}{l}\text { Escola - coordenação - Entrega da } \\
\text { autorização da prefeitura e da regional escolar } \\
\text { (CRE). } \\
\text { Discussão da seleção do aluno } \\
\text { Descrição das características (direção da } \\
\text { escola, coordenadora pedagógica e } \\
\text { professora). }\end{array}$ & $40 \mathrm{~min}$ & $\begin{array}{l}\text { Registro } \\
\text { contínuo }\end{array}$ & \\
\hline $26 / 09 / 2013$ & $\begin{array}{l}\text { Entrevista com a mãe do aluno com } \\
\text { deficiência da sala de aula selecionada. }\end{array}$ & $52 \min 13 \mathrm{~s}$ & Gravação & \multirow{3}{*}{ Etapa 2} \\
\hline $04 / 10 / 2013$ & $\begin{array}{l}\text { Observação da sala: caracterização da rotina } \\
\text { Descrição das características do aluno por } \\
\text { meio do relato do professor (protocolo). }\end{array}$ & $4 \mathrm{~h} 30 \mathrm{~min}$ & $\begin{array}{l}\text { Registro } \\
\text { contínuo }\end{array}$ & \\
\hline $10 / 10 / 2013$ & Reunião com a coordenadora. & $4 \mathrm{~h} 30 \mathrm{~min}$ & $\begin{array}{l}\text { Registro } \\
\text { contínuo }\end{array}$ & \\
\hline $\begin{array}{l}16 / 10 / 2013 \\
17 / 10 / 2013\end{array}$ & $\begin{array}{l}\text { Observação da rotina. Discussão com a } \\
\text { professora do planejamento: inserção de } \\
\text { recursos adaptados. }\end{array}$ & 4h30min & $\begin{array}{l}\text { Registro } \\
\text { contínuo }\end{array}$ & \multirow{6}{*}{ Etapa 3} \\
\hline $18 / 10 / 2013$ & $\begin{array}{l}\text { Uso dos recursos adaptados na rotina da sala } \\
\text { de aula (já avaliados anteriormente). } \\
\text { Inserção de novos recursos: avaliação dos } \\
\text { alunos e da professora. }\end{array}$ & $4 \mathrm{~h} 30 \mathrm{~min}$ & $\begin{array}{l}\text { Registro } \\
\text { contínuo }\end{array}$ & \\
\hline $21 / 10 / 2013$ & $\begin{array}{l}\text { Uso dos recursos adaptados na rotina da sala } \\
\text { de aula. Orientação para o professor. } \\
\text { Visita do professor do AEE. }\end{array}$ & $4 \mathrm{~h} 30 \mathrm{~min}$ & $\begin{array}{l}\text { Registro } \\
\text { contínuo }\end{array}$ & \\
\hline $24 / 10 / 2013$ & $\begin{array}{l}\text { Uso dos recursos adaptados na rotina da sala } \\
\text { de aula. } \\
\text { Orientação para o professor. } \\
\text { Participação da pesquisadora na rotina. }\end{array}$ & $4 \mathrm{~h} 30 \mathrm{~min}$ & $\begin{array}{l}\text { Registro } \\
\text { contínuo }\end{array}$ & \\
\hline $\begin{array}{l}25 / 10 / 2013 \\
01 / 11 / 2013\end{array}$ & $\begin{array}{l}\text { Uso dos recursos adaptados na rotina da sala } \\
\text { de aula. } \\
\text { Orientação para o professor. } \\
\text { Participação da pesquisadora na rotina. } \\
\text { Discussão a respeito do recurso para o aluno } \\
\text { com deficiência. }\end{array}$ & $4 \mathrm{~h} 30 \mathrm{~min}$ & $\begin{array}{l}\text { Registro } \\
\text { contínuo }\end{array}$ & \\
\hline $\begin{array}{l}04 / 11 / 2013 \\
07 / 11 / 2013 \\
08 / 11 / 2013 \\
11 / 11 / 2013 \\
14 / 11 / 2013\end{array}$ & $\begin{array}{l}\text { Uso dos recursos adaptados na rotina da sala } \\
\text { de aula. } \\
\text { Orientação para o professor. } \\
\text { Participação da pesquisadora na rotina. } \\
\text { Discussão a respeito do recurso para o aluno } \\
\text { com deficiência. } \\
\text { Uso do material adaptado com o aluno com } \\
\text { deficiência. }\end{array}$ & $4 \mathrm{~h} 30 \mathrm{~min}$ & $\begin{array}{l}\text { Registro } \\
\text { contínuo }\end{array}$ & \\
\hline
\end{tabular}


Quadro 1

Descrição das Atividades, Tempo de Observação e Instrumentos de Registro

\begin{tabular}{|c|c|c|c|c|}
\hline $29 / 11 / 2013$ & $\begin{array}{l}\text { Orientação e discussão do planejamento com } \\
\text { a profa. da sala de recurso de AEE. }\end{array}$ & $1 \mathrm{~h} 30 \mathrm{~min}$ & Gravação & \\
\hline $\begin{array}{l}02 / 12 / 2013 \\
09 / 12 / 2013\end{array}$ & $\begin{array}{l}\text { Uso dos recursos adaptados na rotina da sala } \\
\text { de aula. } \\
\text { Orientação para o professor. } \\
\text { Participação da pesquisadora na rotina. }\end{array}$ & $4 \mathrm{~h} 30 \mathrm{~min}$ & $\begin{array}{l}\text { Registro } \\
\text { contínuo }\end{array}$ & \\
\hline $\begin{array}{l}12 / 12 / 2013 \\
13 / 12 / 2013\end{array}$ & $\begin{array}{l}\text { Uso dos recursos adaptados na rotina da sala } \\
\text { de aula. } \\
\text { Orientação para o professor. } \\
\text { Participação da pesquisadora na rotina. } \\
\text { Discussão a respeito do recurso para o aluno } \\
\text { com deficiência }\end{array}$ & $5 \mathrm{~h} 30 \mathrm{~min}$ & $\begin{array}{l}\text { Registro } \\
\text { contínuo }\end{array}$ & \\
\hline $18 / 12 / 2013$ & $\begin{array}{l}\text { Avaliação com o conselho da escola e a } \\
\text { professora. }\end{array}$ & $2 \mathrm{~h} 30 \mathrm{~min}$ & $\begin{array}{l}\text { Registro } \\
\text { contínuo }\end{array}$ & \multirow{2}{*}{$\begin{array}{l}\text { Etapa } 3 \\
\text { Avaliação }\end{array}$} \\
\hline $20 / 12 / 2013$ & Avaliação com a coordenadora da escola. & $1 \mathrm{~h} 20 \mathrm{~min}$ & $\begin{array}{l}\text { Registro } \\
\text { contínuo }\end{array}$ & \\
\hline
\end{tabular}

Fonte: produção do primeiro autor

\section{Procedimentos Realizados}

Como pode ser visualizada no quadro 1 , a coleta de informações foi dividida em três etapas, como descrita por Deliberato $(2009,2011,2013)$. Na primeira etapa foram feitos o contato com a escola selecionada e os encaminhamentos das questões éticas solicitadas pelo município. Após a emissão da permissão dos órgãos responsáveis, foi realizada uma primeira reunião na escola com a presença da direção e da coordenação para a discussão dos critérios de seleção da sala de aula que estaria participando do programa.

Ainda na etapa 1 foi feito o contato com a professora selecionada que descreveu os comportamentos do aluno com deficiência, por meio do protocolo de habilidades comunicativas (Paula, 2007). Durante o contato inicial com esta professora foi possível verificar que ela já tinha conhecimento do comportamento da aluna com deficiência e havia feito contato com o professor do atendimento educacional especializado (AEE).

Em seguida, na etapa 2, foi possível ampliar as informações a respeito de Ana, por meio do uso do protocolo de habilidades comunicativas administrado à sua mãe (Delagracia, 2007). Ainda nesta etapa foi possível observar, apresentar e discutir os recursos adaptados com a professora e com os demais alunos da sala.

Na etapa 3, como pode ser visualizado no quadro 1, foram utilizados os recursos adaptados por meio de sistemas gráficos na rotina das atividades programadas pela professora com o auxílio e orientação da pesquisadora. Nesta etapa foi importante o trabalho da pesquisadora em conjunto com a professora e com os demais alunos de forma colaborativa (Rocha, 2013). No final da etapa 3 foi feita a avaliação do trabalho realizado pela professora e a pesquisadora.

\section{Organização das Informações Para Análise}

A gravação da aplicação do protocolo com a mãe foi transcrita na íntegra, assim como as filmagens feitas durante o uso dos recursos adaptados com o aluno com deficiência. As informações do diário de campo foram organizadas por ordem cronológica e as transcrições das filmagens e das entrevistas gravadas foram incorporadas à sequência do registro contínuo feito por meio do diário de campo (Fonseca, 1999) para compor um texto escrito único. Este texto escrito representou a 
triangulação dos dados, ou seja, a articulação de diferentes fontes de coleta de dados (Minayo, 2005; Triviños, 1992).

Análise dos dados. Após estruturação e organização das informações em um texto escrito foram identificados os temas segundo Bardin (2004). As unidades significativas selecionadas foram definidas como tema e subtemas. Os temas e subtemas estão descritos no Quadro 2:

Quadro 2

Temas e Subtemas

\begin{tabular}{|l|l|}
\hline Tema & \multicolumn{1}{|c|}{ Subtema } \\
\hline Rotina da sala de aula & Atividades pedagógicas \\
\cline { 2 - 2 } & Atividades lúdicas \\
\hline \multirow{4}{*}{ Recurso adaptado } & Uso do sistema gráfico com os alunos da sala \\
\cline { 2 - 2 } & $\begin{array}{l}\text { Uso do sistema gráfico com a presença do aluno com } \\
\text { deficiência }\end{array}$ \\
\hline \multirow{2}{*}{$\begin{array}{l}\text { Mediação dos profissionais nas } \\
\text { Capacitação da professora }\end{array}$} & Mediação da professor \\
\cline { 2 - 2 } & Mediação da pesquisadora \\
\cline { 2 - 2 } & Mediação conjunta \\
\hline \multirow{3}{*}{ Avaliação } & Formação inicial \\
\cline { 2 - 2 } & Formação continuada \\
\cline { 2 - 2 } & Características dos alunos \\
\cline { 2 - 2 } & Recurso adaptado \\
\cline { 2 - 2 } & Desempenho dos alunos \\
\cline { 2 - 2 } & Condições de trabalho na sala de aula \\
\hline
\end{tabular}

Fonte: produção do primeiro autor

O tema rotina de sala de aula foi definido como o conjunto das atividades planejadas pelo professor e executadas pelos alunos durante o dia de aula. Os subtemas identificados foram: atividade pedagógica e atividade lúdica.

A definição de atividade foi apoiada em Rocha (2013): atividade envolve diversas tarefas em sequência, ou seja, para realizar uma atividade são necessárias várias ações por quem a realiza. Sendo assim, atividade pedagógica foi definida como a realização de tarefas com conteúdo planejado pelo professor e realizado na rotina da sala. Atividade lúdica, por sua vez, representou a sequência de tarefas nas quais os alunos utilizaram diferentes recursos de forma livre, sem o planejamento prévio da sequência de tarefas.

Segundo Rocha (2010) entende-se como recursos os materiais escolares, materiais pedagógicos, jogos, brinquedos, utensílios utilizados durante as refeições e processos de higiene do aluno, recursos utilizados para posicionamento, e demais materiais e utensílios, além de CD de músicas, livros de histórias e poesias utilizadas pelo aluno no contexto escolar. A autora definiu como recurso adaptado os materiais modificados para as especificidades do aluno com deficiência, incluindo os recursos pedagógicos adaptados, a fim de ampliar o seu desempenho motor, perceptivo, comunicativo e pedagógico.

A definição do tema mediação foi apoiada naquela proposta por Obelar (2011), ou seja, mediação refere-se ao papel do educador que está na sala de aula, auxiliando a criança com ou sem deficiência, por meio de adaptações e materiais diferenciados, a desenvolver-se, a aprender e a vivenciar situações escolares. Os subtemas identificados se referem às pessoas que realizaram a mediação, no caso a professora, a pesquisadora, a professora do AEE e ainda a ação conjunta delas. 
O tema capacitação de professores foi definido como toda informação teórica, prática e teórico-prática realizada com a professora da sala comum ou com a professora do AEE. O subtema formação inicial foi definido como toda informação a respeito da formação inicial do professor e o subtema formação continuada foi envolveu o relato da professora a respeito da formação em serviço e as orientações (verbais e não verbais) da pesquisadora a cerca das adequações necessárias para os alunos com deficiência na sala de aula.

No tema avaliação foram identificados os seguintes subtemas:

Avaliação das Características dos alunos: toda informação obtida a respeito das habilidades e necessidades dos alunos.

Desempenho foi definido como o rendimento e a qualidade da ação do aluno durante sua participação nas atividades utilizando os recursos convencionais e adaptados existentes na escola, ou seja, os resultados obtidos pelo aluno por meio de sua participação (Rocha, 2013).

A avaliação do trabalho na sala de aula representou as informações a respeito das condições físicas do ambiente, assim como do material didático pedagógico utilizado na rotina.

As unidades temáticas foram encaminhadas a dois juízes com experiência na área de Educação Especial, com o objetivo de verificar se os temas e subtemas elencados estavam representados por meio das informações selecionadas. Após análise do material enviado a juízes, foram obtidos os seguintes índices de concordância segundo Carvalho (1996): o índice de concordância entre o pesquisador e juiz A foi de $82,85 \%$ e entre o juiz B e o pesquisador foi de $96,6 \%$.

\section{Resultados e Discussão}

Neste estudo foram analisados os temas e subtemas relacionados ao objetivo proposto: descrever o uso de sistemas gráficos na rotina de uma sala da educação infantil por meio de um programa colaborativo. Cabe destacar que os exemplos foram obtidos por meio de um texto único escrito a partir das informações do registro contínuo no diário de campo, transcrição das entrevistas feitas com a mãe e professora e as sessões filmadas. A seguir, está apresentada a legenda utilizada nos exemplos selecionados para os temas e seus respectivos subtemas:

P: pesquisadora

Prof.: professora da sala de aula

AEE: professora do atendimento educacional especializado

M: mãe do aluno com deficiência

C: coordenadora pedagógica

D: diretora

VD: vice-diretora

A: Ana, aluna com deficiência

AS: alunos da sala

Nomes dos alunos colegas de Ana são também fictícios: Maria, Fábio, Miguel, João, Thaís. ( ) entre parênteses estão as descrições do contexto da realização das atividades para favorecer o entendimento das informações obtidas por meio do registro contínuo.

\section{Tema: Rotina da Sala de Aula - Subtema: Atividades Pedagógicas}

A identificação da rotina escolar pode permitir a inserção de materiais adaptados para a diversidade de alunos na sala de aula. Os profissionais e pesquisadores atuantes com a professora da sala poderiam a partir da identificação das atividades da rotina adequar recursos de modo a permitir a inserção e a ampliação da participação dos alunos nas tarefas pedagógicas, como no caso da aluna 
com deficiência (Rocha, 2010). Os exemplos a seguir ilustram a rotina de atividades a partir informações do planejamento do professor:

Exemplo 1. contato com a professora durante o intervalo dos alunos. Contexto: Apresentação da rotina da sala por meio do protocolo de identificação de habilidades de comunicação

Prof.: A nossa rotina é a que está na parede: segunda é o dia da partilha, terça-feira é o dia da aula de artes e da educação física; quarta-feira é dia da educação física e a atividade da sala de leitura, na quinta-feira é o dia de assistir DVD e na sexta-feira é o dia da cirando do livro. (Cada dia estava representado por meio de um desenho na sequência dos dias da semana na parede).

P.: Então as crianças já sabem o que elas vão trabalhar?

Prof.: Temos a rotina, mas às vezes muda, porque não temos o material, como no caso do vídeo que está quebrado. Tenho trabalhado muito as histórias. Conto na segunda-feira e depois trabalho o conteúdo durante a semana. Como o tema da lagarta. Já fizemos pic nic, as fotos e a história também. Mas eu sigo a rotina e eles já esperam.

Exemplo 2. observação em sala de aula. Contexto: Após a professora realizar a chamada dos alunos no caderno de registro, ela realizava a chamadinha. Esta atividade era direcionada para o reconhecimento do nome dos alunos por meio da escrita. Cada dia a professora tinha um procedimento diferente, mas no final todos os alunos colocavam seus nomes por escrito num painel de madeira na parede.

Prof.: Vou colocar todos os nomes de vocês que estão escritos neste cartão no chão (cada aluno tinha o nome escrito com letra maiúscula numa cartolina laranja). Vou chamar um de vocês para procurar o nome de um dos colegas que eu vou pedir. Então João procura o nome da Maria. Pessoal com que letra começa o nome Maria? AS: com a letra M.

Prof.: Isso, muito bem, igual a letra do nome do Miguel.

AS: Fábio levanta da roda e aponta a letra $\mathrm{M}$ do alfabeto que está fixada na parede acima da lousa.

Prof.: Isso mesmo, Fábio. Pode colocar o nome na chamadinha (painel de madeira fixado na parede)

AS: João coloca o nome da colega no quadro de madeira fixado na parede (chamadinha) e volta para a roda. Ele coloca o nome selecionado na coluna dos nomes das meninas.

Os exmplos 1 e 2 permitem identificar tanto no relato da professora quanto na observação da atividade que há preocupação na organização das tarefas a serem realizadas pelos alunos. Rocha (2013) em sua pesquisa identificou que o planejamento da rotina por meio de tarefas préestabelecidas permite a possibilidade de analisar a atividade e adaptá-la quando necessário para os alunos que necessitam de algum recurso de tecnologia assistiva.

Os exemplos do subtema "uso de sistema gráficos com os alunos" poderão descrever a inserção dos recursos a partir da sistematicidade da rotina estabelecida pela professora, como pode ser visualizado a seguir:

\section{Tema: Recurso Adaptado - Subtema: Uso do Sistema Gráfico Com os Alunos da Sala}

Exemplo 3. observação da sala de aula. Contexto: A pesquisadora introduz o recurso adaptado na sala de aula apresentando o material com a professora e discutindo a respeito com os alunos. 
Prof.: A P. trouxe um material muito bonito para a classe. Ela vai trabalhar com a A., mas pensou em todos vocês. Tudo que ela vai fazer com a Ana, ela também pensou em vocês, Ela quer ajudar. É bacana, muito legal. Eu gostaria de todo coração agradecer o que a $\mathrm{P}$. fez.

P: Eu é que agradeço a oportunidade de trabalhar com vocês. (Em seguida a pesquisadora pega o material e os coloca em direção a todas as crianças que estão na roda e inicia a atividade com o recurso adaptado)

P: Vejam este calendário é parecido com o que vocês já têm na sala. Ele ainda não está pronto, mas vocês vão me ajudar. Olhem, vamos ver os dias da semana. (Pesquisadora vai apontando o local do conteúdo no calendário construído). Aqui está escrito: mês. Vamos ler juntos.

P e AS: Ou tu bro (a P leu com os alunos oferecendo apoio da leitura com o dedo em cada sílaba da palavra impressa). Olha aqui tem o ano: 2013. Eu também já fiz as palavras escritas dos outros meses e anos para vocês usarem depois. Aqui está escrito domingo: está em vermelho: começa a semana. Vamos ver os demais.

AS: Segunda-feira, terça-feira... (P. oferece o apoio verbal e visual indicando com o dedo cada sílaba da palavra lida).

P: Aqui é o sábado. Vejam está em vermelho: é o ultimo dia da semana. Depois começa tudo de novo. Aqui estão os números, mas eu vou mostrar as figuras do tempo, para que depois eu possa fazer mais e deixar com vocês. Aqui estão as imagens de chuva, sol, calor, nublado. Estas figuras vão ajudar vocês a preencher o calendário de vocês e da Ana.

Exemplo 4. observação na sala de aula. Contexto: A P. introduz recurso adaptado a respeito dos combinados entre a professora e os alunos.

P: Vocês lembram que vocês me ajudaram a escrever os combinados? Então eu trouxe as figuras para vocês me falarem se vocês acham que elas estão boas, o que vocês e a professora acham do material.

AS: No momento em que as crianças foram pegando as imagens, elas perceberam a escrita e colocaram o dedo para tentar ler.

AS: Essa figura é chuva (disse a Thaís)

P: Isso mesmo, vamos ler o que está escrito. Neste momento a professora auxiliou a aluna pegando no dedo dela e lendo: chu_va. E assim fez com outras imagens.

AS: As crianças que não conseguiam ler, mas reconheciam as imagens foram tentando ler as palavras impressas com apoio do dedo, a partir do reconhecimento da imagem pictográfica.

P: Olhem esta figura. A P. mostrou a figura que representa ficar em fila.

AS: O que é isto?

Prof.: É uma pessoa atrás da outra. É uma fila.

P: A pesquisadora foi mostrando cada imagem que representava os combinados com a sala, indicando a palavra impressa acima da figura. (Combinados: lavar a mão, fazer fila, sentar na roda, fazer silêncio, lavar o rosto, não bater no amigo, ajudar o amigo, guardar o material). Após mostrar as imagens dos combinados, a P perguntou: está faltando algum combinado?

Prof.: Não. Está bom.

Os exeplos 3 e 4 descrevem a pesquisadora em conjunto com os alunos e professora avaliando e adequando as imagens dos sistemas gráficos para tarefas e conteúdos que fazem parte da rotina, como, o calendário e os combinados estabelecidos entre o professor e os alunos para a organização 
das regras da sala de aula. É possível perceber que no momento em que a P. e os alunos exploram e discutem a respeito do conteúdo e formato dos materiais, os alunos acabam sendo inseridos em estímulos visuais que transmitem significado e propiciam a realização da tarefa, como no caso da leitura, para aqueles alunos que ainda não conseguem realizá-la.

Massaro (2012) organizou e inseriu um programa de intervenção por meio de sistemas gráficos em colaboração com a professora de uma sala da educação infantil para alunos com severa deficiência e para alunos sem deficiência. A autora descreveu a ampliação da participação dos alunos com deficiência nas tarefas da rotina estabelecida pelo planejamento do professor e identificou o interesse e a facilidade das crianças não deficientes no uso das imagens gráficas, principalmente nas músicas utilizadas nas atividades pedagógicas e lúdicas.

Além destas questões pontuadas pela pesquisadora, também seria possível alertar que o envolvimento dos alunos da escola com os sistemas gráficos pode permitir a aquisição da competência em usar o sistema gráfico com alunos com deficiência (Alves, 2006; Deliberato, 2012). A literatura discutiu a necessidade dos alunos com deficiência estarem em ambientes adequados à diversidade de alternativas de comunicação sendo a escola um meio importante para prover o suporte a estas formas (Von Teztchner, 2009).

No subtema, a seguir, é possível identificar o uso do sistema gráfico direcionado para o aluno com deficiência, mas com o envolvimento dos demais alunos:

\section{Subtema: Uso do Sistema Gráfico Com a Presença do Aluno Com Deficiência}

Exemplo 5. observação da sala de aula. Contexto: Uso do calendário adaptado com os alunos e A.

Prof.: ntem foi que dia?

AS: Domingo

Prof.: Teve aula?

AS: Não.Prof.: Então vamos pôr a figura que tem um $\mathrm{X}$

P: A pesquisadora foi ao armário e pegou o material por meio dos sistemas gráficos.

Cada gaveta tinha uma imagem representando o conteúdo. Vejam: cada gaveta tem uma figura: sol, chuva, vento.

Prof.: Olha nesta gaveta tem o sol. O sol está na gaveta de cor amarela.

P: Neste momento a pesquisadora pega os materiais ampliados e com EVA para A. e os coloca bem próximo a ela. A aluna tenta pegar a caixa dos materiais e P. diz: A., vamos prestar atenção. A aluna deita e, neste momento, a professora explicava a tarefa da alface e vai ao quadro e escreve a palavra alface. A pesquisadora pega o apoio preto com linhas de velcro e a cesta de letras e tenta escrever a palavra "alface" para A. (apoio à fala e escrita da professora). Neste momento as crianças também querem manusear o material e A. tenta pegar o material para tirar e pôr no velcro. AS: As crianças ficam muito interessadas no material e começam a soletrar as palavras e com o apoio do dedo esboçam uma leitura silabada. Vão verbalizando letra por letra e as sílabas, principalmente a Thaís.

A ativiade com calendário faz parte da rotina diária da sala de aula. O material já havia sido apresentado e utilizado com os alunos da sala sem a presença de A., a criança com deficiência. $O$ exemplo 5 descreve tanto a pesquisadora oferecendo o modelo de uso de um material no contexto de uma tarefa da rotina, como também ilustra a participação das outras crianças. A formação de interlocutores falantes no contexto das formas alternativas de comunicação tem sido discutida e apontada como um caminho accessível para o aluno com deficiência não falante ampliarem sua participação nas situações comunicativas e acadêmicas (Deliberato, 2013; Massaro, 2012; Nunes et al., 2011). 
Neste processo de capacitação de parceiros de comunicação e suporte das formas alternativas de comunicação, a mediação dos interlocutores competentes no uso dos sistemas gráficos é fundamental. Os exemplos, a seguir, ilustram a participação da professora, e o trabalho colaborativo da professora com a pesquisadora nas tarefas com os alunos.

\section{Tema: Mediação dos Profissionais nas Atividades - Subtema: Mediação da Professora}

Exemplo 6. observação da sala de aula. Contexto: a professora está utilizando e explicando a tarefa no caderno didático.

Prof.: Após a tarefa do calendário, a professora pegou o caderno didático. Cada criança tem o seu caderno. Então disse: Sei que alguns de vocês já fizeram a tarefa, mas muitos ainda não fizeram. Então vamos para a primeira página. Temos o alfabeto. Vocês sabem o nome das letras? Vamos ler. Será que os desenhos são os mesmos que nós temos no nosso quadro? (a professora relacionou o alfabeto do caderno com o alfabeto fixado na parede da sala de aula)

AS: Não. As crianças e a professora foram lendo as letras e os desenhos correspondentes, como, por exemplo: letra J - figura do jacaré.

Prof.: Agora vamos para a página 3. Vejam o calendário do mês de agosto. Quantos dias têm, vamos contar.

AS: As crianças tiveram dificuldade em entender a contagem do mês. A professora necessitou passar aluno por aluno e contar juntos.

Prof.: Vejam depois vocês devem colocar o número 31 no quadradinho.

\section{Subtemas: Mediação da Pesquisadora e Mediação Conjunta}

O exemplo 7 ilustra a atuação da pesquisadora em uma atividade com os alunos da sala de aula e o exemplo oito descreve a atividade realizada com A., a aluna com deficiência, por meio das ações conjuntas da pesquisadora e da professora de AAE.

Exemplo 7. observação da sala de aula. Contexto: pesquisadora auxiliando na atividade de percepção tátil com as crianças. A tarefa foi em grupo: uma das crianças do grupo desenhou a mão no papel e com as demais colaram material sensitivo, como areia, barbante, pedrinhas, algodão.

Prof.: A professora dividiu a sala em grupos. Cada grupo ficou sentado à mesa. Olha o que vocês vão fazer: uma atividade em grupo. Quem tiver a mão maior do grupo vai ser escolhido para que vocês façam o desenho no papel. Depois a P vai passar cola e aí cada grupo vai colar alguma coisa diferente: areia (verde), tachinha, algodão, EVA colorido cortado, palha, barbante. Ontem nós passamos no corpo: lixa e algodão. O que vocês gostaram mais? Algodão é mais macio e a lixa é mais áspera. AS: O algodão - disseram as crianças.

P: P foi passando nas mesas. Bem, vamos ver quem tem a mão maior: Miguel vamos comparar a sua mão com a mão da Thais e com as outras crianças. Em seguida a P. auxiliou as crianças a escolherem quem do grupo colocaria a mão para ser desenhada no papel. Além disso, a P. foi medindo as mãos das crianças colocando-as uma mão contra mão. Então quem tem a maior mão?

AS: Miuel

P: Em seguida, solicitando para abrir bem os dedos, M. colocou a mão na folha de papel e a P. desenhou o contorno. M. abre bem os dedos para podermos contornar sua mão e ficar um desenho bem bonito. Agora vamos passar cola e sentir o que vamos colar: algodão. Ele é bem macio. 
Exemplo 8. observação da sala de aula. Contexto: mediação da pesquisadora e da professora do AEE na sala regular com o aluno com deficiência.

AEE: AEE foi pegar brinquedos, laptop e outros brinquedos com estímulo sonoro. Ana fez atividade lúdica com a boneca: AEE fazia como que se estivesse fazendo comida. Por um instante Ana pegou a boneca e colocou nos braços e parecia participar da atividade, sem manter contato visual com a professora de AEE. P: Neste momento a pesquisadora somente observava a atuação da AEE com a criança: os demais alunos estavam realizando a atividade do prato sensorial (colagem de materiais sensitivos num prato de papelão para representar um prato de comida). Ana estava fora do contexto. Neste instante a pesquisadora se aproximou da Prof e perguntou: Prof. eu poderia fazer um prato sensorial com Ana?

Prof: Pode sim. Pode pegar o material para fazer. Vou te ajudar.

P: Pesquisadora se aproximou de A. e da AEE com um prato de papelão com o arroz, feijão, alface de papel e ovo. P. pegou a mão de A. e perguntou para AEE: qual é a mão da preferência dela?

AEE: Ela usa a esquerda. Ela é canhota.

P: A pesquisadora pegou na mão de A. e explorou os materiais antes de colar. Cada material explorado, a P oralizava a situação.

AEE: olha que legal A. Você está fazendo a comida para boneca. Vamos dar comida para a boneca.

P: Muito bem, agora vamos colocar seu trabalho junto com os outros na mesa da professora.

Os exmplos 6 e 7 descrevem situações nas quais, tanto a professora quanto a pesquisadora, oferecem auxílio e informações que contribuem para os alunos entenderem o novo conteúdo. A pesquisadora colaborou com a professora na rotina, o que permitiu maior interação e atuação junto aos alunos. Tal interação possibilitou ações conjuntas na rotina, principalmente quando a tarefa a ser realizada necessitava da colaboração entre os profissionais, como no exemplo 8. As ações entre pesquisadora, professora da sala e professora do AEE permitiram a inserção e participação da aluna com deficiência no conteúdo trabalhado com os demais alunos da sala. O trabalho colaborativo entre professor e pesquisador utilizado na educação infantil foi discutido por Rocha (2010, 2013). A autora operacionalizou a proposta de Manzini e Souza (2002), ou seja, por meio de trabalho colaborativo entre a pesquisadora e a professora foi possível prescrever, selecionar, adaptar, implementar e avaliar o uso dos recursos de tecnologia assistiva com crianças com paralisia cerebral na sala de aula.

Araujo, Deliberato e Braccialli (2009) discutiram a necessidade de formação de profissionais no contexto da área da comunicação alternativa. Os autores argumentaram que frente à diversidade de pessoas com deficiência e diante das novas abordagens de trabalho com as pessoas com deficiência há necessidade que os profissionais da saúde e educação estejam formados para a diversidade de possibilidades de comunicação.

Swengel e Marquette (1997) consideraram a equipe de trabalho com a comunicação alternativa como um time, ou seja, um grupo de pessoas com diferentes formações profissionais que investem no trabalho conjunto para alcançar metas em comum. Os mesmos autores salientaram a importância do trabalho colaborativo, discutindo a importância da atuação de diferentes áreas do conhecimento não só para garantir as habilidades de comunicação, mas também a qualidade de vida da pessoa com deficiência. Na formação de profissionais, os autores citados destacaram a formação dos professores, quer na formação inicial e continuada, como pode ser visualizada nos exemplos a seguir: 


\section{Tema: Capacitação da Professora - Subtemas: Formação Inicial e Continuada}

Neste tema o exemplo nove caracteriza o subtema formação continuada e o exemplo 10 o registro discute a respeito do subtema formação inicial.

Exemplo 9. Observação da sala de aula e orientação para professora. Contexto: Discussão do recurso adaptado para sala de aula: calendário. Após a atividade da chamadinha a professora focaliza o calendário: dia da semana, dia do mês e discute o período do dia e as questões do tempo: sol, chuva, nublado, etc. A professora tinha fixado na parede um calendário do mês, com números e letras com pouco destaque visual e os desenhos representativos do tempo. Os desenhos utilizados para representar o tempo também não estavam com clareza visual, ou seja, eram desenhos feitos por alunos com traçados fora do contexto representativo. Tais desenhos poderiam não ser identificados por um aluno com deficiência ou mesmo um aluno com alterações dos aspectos de discriminação visual. A seguir o momento de discussão do material adaptado:

P: Enquanto as crianças faziam a tarefa, a P foi mostrar o material que havia combinado com a professora: calendário para sala. No momento que retirou o material, a professora me disse:

Prof.: Nossa que lindo, foi você quem fez?

P: Foi.

Prof.: Eu queria você sempre para trabalhar comigo.

P: Mas eu também gostaria de trabalhar com pessoas como você: organizada e planeja suas atividades. É muito bom trabalhar com quem planeja e tem rotina. Bem, tive que colocar EVA mais grossa e plastificar as imagens de tempo, números, etc.

Assim A. pode utilizar e também pode ter maior durabilidade. Vou também plastificar os demais materiais.

Prof.: Mas não precisa. Você imprimiu na sua casa?

P: Imprimi.

Prof.: Nossa... Ficou muito bom!

P: aqui estão letras e números de tamanhos diferentes.

Prof.: Nossa que bom!

AS: Neste instante uma aluna chega perto e começa a pegar as imagens, os números.

P: Vai fazer sua tarefa, depois eu mostro o novo calendário para todos vocês.

A aluna ficou perto e continuava explorando os números, alterando os lugares e inserindo as images relacionadas ao tempo.

\section{Subtema: Formação Inicial}

Exemplo 10. Observação da sala de aula e orientação para professora. Contexto: orientação para a professora.

Prof.: Então, porque você acha que as salas especiais fecharam?

P: Bem, grande parte das salas acabou se tornando depósitos de crianças com deficiência. Essa é a grande questão. Há toda uma discussão de uma política de inclusão, dos direitos para que todos tenham acesso a uma escola com qualidade. Todos os alunos deveriam compartilhar do mesmo espaço na escola. Enfim, muitos professores acabaram não conseguindo dar conta dos alunos com deficiência e foi um problema.

Prof.: Ah!!

P: Eu acho que cada criança tem sua especificidade e precisa de pessoas especializadas para trabalhar com elas. 
Prof.: É como a professora da sala de recurso daqui. Quando eu cheguei aqui, ela trabalhava com alunos cegos. Nossa como ela trabalhava bem. Eu já tive aluno cego que ela colocou no ensino comum. Primeiro ela trabalhava lá, e quando eles já tinham condição, iam para a sala comum. Agora ela tem que atender tudo. P: Então mesmo fazendo cursos de especialização, habilitação, uma professora não dá conta de tudo.

Prof.: Então eu acho que todos os cursos de licenciaturas deveriam ter alguma coisa. P: É mas deveriam sim, porque é lei. No caso da LIBRAS é obrigatório para as licenciaturas e os cursos de fonoaudiologia.

Prof.: Eu tive uma disciplina a respeito da deficiência.

Os exemplos citados estão em consonância com o estudo de Rocha (2010). A autora verificou que além de garantir os recursos adaptados para o aluno na escola é fundamental que os profissionais estejam capacitados a oferecer estratégias e oportunidades para o aluno utilizá-los. Somente o conjunto de ações de diferentes profissionais é capaz de garantir a acessibilidade do aluno com deficiência durante as atividades escolares. Os resultados do estudo de Rocha indicaram que de fato, a implementação, a avaliação e o acompanhamento do uso do recurso adaptado são um processo que está diretamente relacionado às demandas do aluno, da dinâmica escolar, das atividades pedagógicas e do envolvimento do professor no planejamento.

Neste contexto de discussão, Rocha e Deliberato (2012) e Pelosi e Nunes (2010) argumentaram que não é de responsabilidade do professor exclusivamente identificar, prescrever, construir e criar estratégias para o uso da tecnologia assistiva no contexto escolar. É necessário o envolvimento de todos os profissionais da escola, dos alunos, das famílias e, também, de redes de apoio formadas por profissionais de diferentes setores, como os profissionais da saúde.

Rocha e Deliberato (2012), Rocha (2013), Nunes et al. (2011) alertaram para a necessidade da identificação das habilidades e necessidades dos alunos para a implementação de recursos adaptados por meio de sistemas gráficos. Os exemplos, a seguir, ilustram informações a respeito das características dos alunos que poderiam colaborar com o planejamento dos materiais para a sala de aula.

\section{Tema: Avaliação - Subtema: Características dos alunos}

Exemplo 11. entrevista com o professor da sala de aula. Contexto: Pesquisadora e professora discutem das características do aluno com deficiência no momento em que os alunos estão no lanche. (No momento do lanche os alunos ficam com uma funcionária da escola)

Prof.: Eu acho que a A. pode aprender, mas ela fica pouco tempo numa atividade e baba muito. Quando ela consegue fazer uma atividade, ela baba mais. Quando ela é obrigada a fazer alguma coisa, ela fica irritada, fala palavrão. Percebo que ela fala os palavrões de forma correta.

P.: Ela usa óculos?

Prof.: Ela já veio de óculos, mas não fica com ele. Ela joga e é um sufoco achar. Eu percebo que ela vem bem cuidada com roupa limpa. Ela sai suja daqui, mas vem limpa. Ela tem pouca atenção nas tarefas, fica pouco tempo.

Exemplo 12. Entrevista com a mãe do aluno com deficiência. Contexto: Relato da mãe da aluna com deficiência a respeito do comportamento de sua filha.

M: Ela é uma criança é assim ela é calma, ela é no sentido de carinho. Ela é uma criança que não pode ser contrariada. Se ela for contrariada acaba o mundo dela. Ela é uma pessoa inteligente. Não esquece o que você fala para ela.

P: Você acha que ela entende bem as coisas?

M: Entender.... Acho que ela não entende bem, mas ela guarda. 
Os exemplos citados ilustram que há necessidade de ações colaborativas para a inserção de recurso adaptado nas tarefas pedagógicas, mas há igualmente necessidade de ações colaborativas para o planejamento da estratégia que permite a participação do aluno com alguma especificidade. $\mathrm{O}$ exemplo 11 indica que o aluno com deficiência pode ter alteração visual, o que indica a necessidade dos cuidados com o tamanho da imagem, assim como o contraste de cor a ser utilizado. A informação obtida por meio do exemplo 12 pode direcionar o professor e demais profissionais para duas questões: a) planejar estratégias que permitam a criança a possibilidade de ampliar o tempo de atenção nas tarefas e b) sistematizar orientações à família a respeito do desenvolvimento da linguagem e adequação de comportamentos na rotina de atividades.

Além de organizar e inserir as adequações, há necessidade do acompanhamento dos alunos nas tarefas realizadas. Essa avaliação permite a manutenção e a alteração do recurso e das estratégias estabelecidas para a sala de aula e para o aluno com deficiência. Os exemplos, a seguir, demonstram situações de avaliação imediata da tarefa realizada.

\section{Subtema: Desempenho dos Alunos}

Exemplo 13. observação da sala de aula. Contexto: A professora conversou com os alunos na roda a respeito da realização da tarefa feita com as letras e números.

Prof.: A tarefa está muito legal, gostei muito, mas, podemos melhorar. No geral está

bom, mas, precisamos prestar a atenção para ficar melhor: não cortar as letras e os

números e também não colar de ponta cabeça. Ma, estava muito bom, mas, precisa melhorar. Da próxima vez, vamos melhorar.

O exemplo possibilitou o incentivo da professora a respeito do desempenho dos alunos na tarefa realizada, mas também a professora os alertou a respeito dos aspectos que poderiam melhorar numa próxima tarefa.

Outro aspecto de avaliação importante para a implementação de recursos adaptados na sala de aula foram se refere às condições do material didático e das condições ambientais como demonstrados nos exemplos 14 e 15:

\section{Subtema: Condições de Trabalho na Sala de Aula}

Exemplo 14. Observação e entrevista com a professora. Contexto: A professora relata a dificuldade dos alunos em função do material didático

AS: Poucas crianças sabiam o mês do seu aniversário. A professora foi um por um e em seguida as crianças circularam o nome do mês. As crianças não conseguiam realizar a tarefa do livro didático.

Prof.: A professora comentou: Veja como é difícil esse material para as crianças. Tem uma coisa escrita aqui e tem que virar para fazer.

P: É ele tem comando muito difícil. Deveria ser na mesma página e frases mais simples.

Prof.: Antes era pior ainda. A letra era minúscula, igual a esta aqui do final da página. Eles colocam pessoas catedráticas, mas que não sabem o que acontece na sala. $\mathrm{O}$ aluno pode ser prejudicado na sua avaliação.

Exemplo 15. Entrevista com o professor. Contexto: Condições a respeito da quantidade de alunos em sala de aula.

Prof.: Viu, como essa quantidade de alunos está boa. Veja hoje, a quantidade, eu consigo dar conta e dar assistência melhor.

P: Mesmo assim, com quantidade menor, você teria que ter uma pessoa auxiliando, porque não vai dar conta da A. Ela tem comportamento difícil. 
Prof.: Você já tem doutorado?

P: É já tenho mais que doutorado.

Prof.: Então as pessoas que fazem doutorado tinham que saber o que acontece na sala.

P: É eu penso assim. Eu adoro ficar em sala e conhecer como é para poder propor uma pesquisa que colabore com a rotina da sala.

Prof.: Se não fosse você e a AL eu não conseguiria dar conta da A.

P: Você tem razão. Vou falar com a AEE para combinar a rotina. Você também deveria ter uma sala com menos alunos.

A literatura tem discutido a necessidade de a escola estar adequada à diversidade de alunos com necessidades especiais. As adequações não devem ser somente direcionadas à acessibilidade física, mas para outros elementos fundamentais para o processo de ensino e aprendizagem escolar, como, no caso da acessibilidade comunicativa, os materiais didáticos pedagógicos e suas adequações, entre outros fatores estabelecidos pela Lei da acessibilidade (ABNT, 2004).

O exemplo 14 está relacionado com a avaliação do professor a respeito do material didático utilizado para as tarefas pedagógicas. Segundo o exemplo, o material está inadequado para os alunos da sala de aula em virtude das questões de forma e conteúdo. Enquanto que no exemplo 15, o professor relatou a sua preocupação com a dificuldade em dar atenção às necessidades de cada aluno considerando o número de alunos que frequenta a sala de aula.

\section{Considerações finais}

Os resultados obtidos por meio da análise dos temas e subtemas revelaram que: a) as crianças usaram o sistema gráfico na rotina de atividades, b) o sistema gráfico auxiliou as crianças na leitura das palavras, c) o professor inseriu o sistema gráfico a partir da mediação da pesquisadora, d) a rotina das atividades pedagógicas planejadas pela professora facilitou a inserção do sistema gráfico na sala de aula, favorecendo aos alunos participantes o suporte no contexto das formas alternativas de comunicação, e) os recursos utilizados por meio dos sistemas gráficos favoreceram a participação de Ana, a aluna com deficiência a partir das ações colaborativas entre a pesquisadora, a professora da sala de aula e e professora do atendimento educacional especializado.

O trabalho colaborativo por meio de sistemas gráficos permitiu reforçar a necessidade da escola e dos demais profissionais estarem atentos à inserção da tecnologia assistiva na rotina de atividades pedagógicas, notadamente aqueles serviços, recursos, estratégias e sistemas gráficos da área da comunicação alternativa.

Embora o estudo tenha limitações, principalmente por ter sido desenvolvido somente em uma sala de aula, os resultados reforçam a necessidade de ações colaborativas para atuar no contexto do uso de recursos da tecnologia assistiva. Os dados indicaram igualmente a importância da participação das crianças da sala de aula no contexto das novas tecnologias, reforçando, com isto, o papel do interlocutor competente no uso dos sistemas gráficos.

\section{Referências}

Associação Brasileira de Normas Técnicas. (2004). Acessibilidade a edificações, mobiliário, espaços e equipamentos urbanos. NBR 9050.

Alves, V. A. (2006). Análise das modalidades expressivas de um aluno não falante frente a diferentes interlocutores durante a situação de jogo. Dissertação (Mestrado em Educação) - Faculdade de Filosofia e Ciências, Universidade Estadual Paulista, Marília. 
Araujo, R. C. T., Deliberato, D., \& Braccialli, L. M. (2009). A comunicação alternativa como área do conhecimento nos cursos da educação e da saúde. In D. Deliberato, M. J. Gonçalves, \& E. C. Macedo (Orgs.), Comunicação alternativa: Teoria, prática, tecnologias e pesquisa (pp. 275-284). São Paulo: Memnon.

Bardin, L. (2004). Análise de conteúdo. Lisboa: Edições 70.

Beukelman, D. R., \& Mirenda, P. (2007). Augmentative \& alternative communication: Supporting children \& adults with complex communication needs. Baltimore: Paul H. Brookes Publishing, 2007.

Binger, C., \& Light, J. (2007). The effect of aided AAC modeling on the expression of multi-symbol messages by preschoolers who use AAC. Augmentative and Alternative Communication, 23(1), 30 43. http://dx.doi.org/10.1080/07434610600807470

Brasil, Decreto. (2004). Decreto no 5296 de 2 de dezembro de 2004. Brasília. Dispinível em http://www.planalto.gov.br/ccivil_03/_ato2004-2006/2004/decreto/d5296.htm. Acesso 25 de fev. 2014.

Brekke, K. M., \& Von Tetzchner, S. (2003). Co-construction in graphic language development. In S. von Tetzchner \& N. Grove (Eds.), Augmentative and alternative communication: Developmental issues (pp. 176-210). London, UK: Whurr.

Capellini, V. L. M. F., \& Mendes, E. G. (2007). O ensino colaborativo favorecendo o desenvolvimento profissional para a inclusão escolar. Educere et Educare Revista de Educação, 2(4), 113-128.

Carvalho, A. M. P. (1996). O uso do vídeo na tomada de dados: pesquisando o desenvolvimento do ensino em sala de aula. Pro-posições, 7(1), 5-13

CAT - Comitê de Ajudas Técnicas. Ata da Reunião VII, dezembro de 2007 do Comitê de Ajudas Técnicas. Secretaria Especial dos Direitos Humanos da Presidência da República. (CORDE/SEDH/PR), 2007. Disponível em: http://www.infoesp.net/CAT_Reuniao_VII.pdf. Acesso em 07 de março de 2015.

DeCoste, D. C. (1997). AAC and individuals with physical disabilities. Augmentative Alternative Communication Assessment Strategies. In S. L. Glennen \& D. C. De Coste (Eds), The handbook of argumentative and alternative communication (pp. 363-389). San Diego: Singular.

Delagracia, J. D. (2007). Desenvolvimento de um protocolo para avaliação de habilidades comunicativa para alunos não falantes em situação familiar. Dissertação (Mestrado em Educação) - Faculdade de Filosofia e Ciências de Marília, Universidade Estadual Paulista, Marília.

Delgado, S. M. M. (2011). O papel do interlocutor no processo de interação e comunicação com jovens não falantes. In L. R. Nunes, P. L. Quiterio, C. C. Walter, C. R. Schirmer, C. R., \& P. Braun (Eds), Comunicar é preciso: em busca das melhores práticas na educação do aluno com deficiência (pp. 59-69). Marília: ABPEE.

Deliberato, D. (2013). Comunicação alternativa na escola: Possibilidades para o ensino do aluno com deficiência. In A. P. Zaboroski \& J. P. Oliveira (Eds.), Atuação da Fonoaudiologia na escola: Reflexões e práticas (pp. 71-90). Rio de Janeiro: WAK Editora.

Deliberato, D. (2011). Comunicação alternativa e educação especial: Ações inclusivas para crianças e jovens com deficiência In F. C. Capovilla. (Ed), Transtornos de aprendizagem 2: Da análise laboratorial e da reabilitação clínica para as políticas públicas de prevenção pela via da educação (pp.181186). São Paulo: Memnon.

Deliberato, D. (2009). Comunicação alternativa na escola: Habilidades comunicativas e o ensino da leitura e escrita. In D. Deliberato, M. J. Gonçalves, \& E. C. Macedo (Orgs.), Comunicação alternativa: Teoria, prática, tecnologias e pesquisa (pp. 235-243). São Paulo: Memnon.

Deliberato, D., \& Manzini, E. J. (2006). Fundamentos introdutórios em comunicação suplementar e/ou alternativa. In K. F. Genaro, D. A. C. Lamônica, \& M. C. Bevilacqua (Eds.). O Processo 
de comunicação: contribuição para a formação de professores na inclusão de indivíduos com necessidades educacionais especiais (pp. 243-254). São José dos Campos: Pulso.

Deliberato, D., Manzini, E. J., \& Guarda, N. S. (2004). A implementação de recursos suplementares de comunicação: Participação da família na descrição de comportamentos comunicativos dos filhos. Revista Brasileira de Educação Especial, Marília, 10(2), 199-220.

Falkembach, E. M. F. (1987). Diário de campo: Um instrumento de reflexão. Contexto e Educação, 2 (7), 19-24.

Fernandes, A. S. (2001). A comunicação alternativa na educação especial. Temas sobre Desenvolvimento, 10(58-9), 85-88.

Fonseca, C. (1999). Quando cada caso NÃO é um caso de pesquisa etnográfica e educação. Revista Brasileira de Educação, 10, 58-78.

Gulens, M., Kerbel, S., \& Nobel, L. (2006, julho). Just talk: Practical strategies for developing functional communication using AAC. In Proceedings of the Biennial Conference of the International Society for Augmentative and Alternative Communication (pp. 209-211), Duesseldorf: ISAAC.

Light, J. C. (2003). Development of communicative competence by individuals who use AAC. In J. C. Light, D. R. Beukelman, \& J. Reichle (Eds.), Communicative competence for individuals who use AAC: From research to effective practice (pp. 3-38). Baltimore: Paul H. Brookes.

Light, J., \& McNaughton, D. (2013). Putting first: Re-thinking the role of technology in augmentative and alternative communication intervention. Augmentative and Alternative Communication, 29(4), 299-309. http://dx.doi.org/10.3109/07434618.2013.848935

Machado, A. C., Bello, S. F., \& Almeida, M. A. (2012). O papel consultivo do fonoaudiólogo: Algumas reflexões sobre a consultoria colaborativa na escola regular. Rev. Educação Especial, Santa Maria, 25(43), 233-248.

Manzini, E. J., \& Santos, M. C. F. (2002). Portal de ajudas técnicas para a educação: equipamento e material pedagógico para educação, capacitação e recreação da pessoa com deficiência - recursos pedagógicos adaptados. Brasília: MEC.

Massaro, M. (2012). Música por meio de sistemas de comunicação alternativa: Inserção do aluno com deficiência na atividade pedagógica. Dissertação (Mestrado) - Faculdade de Filosofia e Ciências, Universidade Estadual Paulista, Marília.

Mayer-Johnson, R. (2004). The Picture Communication Symbols P.C.S. Software Boardmaker. Porto Alegre: Clik Tecnologia Assistiva.

Mendes, E. G. (2008). Inclusão escolar com colaboração: Unindo conhecimentos, perspectivas e habilidades profissionais. In L. A. Martins, J. Pires, \& G. N. Pires. (Orgs.), Políticas e práticas educacionais inclusivas (pp. 19-52). Natal: EDUFRN.

Minayo, M. C. S. (2005). Introdução. In Minayo, M. C. S., Assis, S. G., \& Souza, E. R. (Orgs.), Avaliação por triangulação de métodos: Abordagem de programas sociais. Rio de Janeiro: Editora Fiocruz.

Mirenda, P., \& Locke, P. (1989). A comparison of symbol transparency in nonspeakng persons with intellectual disabilility. Journal of Speech and Hearing Disorders, 54, 131-140. http://dx.doi.org/10.1044/jshd.5402.131

Nunes, L. R. d'O. P, Quiterio, P. L., Walter, C. C. F., Schirmer, C. R., \& Braun, P. (2011). Comunicar épreciso: Em busca das melhores práticas na educação do aluno com deficiência. Marília: ABPEE.

Obelar, F. (2011). A importância da mediação no contexto de uma sala inclusiva. In L. R. Nunes, P. L. Quiterio, C. C. Walter, C. R. Schirmer, \& P. Braun (Eds.), Comunicar é preciso: Em busca das melhores práticas na educação do aluno com deficiência (pp. 71-79). Marília: ABPEE. 
Paula, R. (2007). Desenvolvimento de um protocolo para avaliação de habilidades Comunicativas de alunos não falantes em ambiente escolar. Dissertação (Mestrado em Educação) - Faculdade de Filosofia e Ciências, Universidade Estadual Paulista, Marília.

Pelosi, M. B., \& Nunes, L. R. d'O. P. (2010). A inclusão dos alunos com deficiência nas escolas regulares. Temas sobre desenvolvimento, 17(99), 99-103.

Quiterio, P. L., \& Brando, A. M. (2011). Alunos não oralizados: A voz através da comunicação alternativa e a vez através das habilidades sociais. In L. R. Nunes, P. L. Quiterio, C. C. Walter, C. R. Schirmer, \& P. Braun. (Eds.), Comunicar é preciso: Em busca das melhores práticas na educação do aluno com deficiência (pp. 47-58). Marília: ABPEE.

Rocha, A. N. D. C. (2013). Recursos e estratégias da tecnologia assistiva a partir do ensino colaborativo entre profissionais da saúde e da educação. Tese (Doutorado) - Faculdade de Filosofia e Ciências, Universidade Estadual Paulista, Marília.

Rocha, A. N. D. C. (2010). Processo de prescrição e confecção de recursos de tecnologia assistiva na educação infantil. (Mestrado em Educação) Faculdade de Filosofia e Ciências, Universidade Estadual Paulista. Marília.

Rocha, A. N. D. C., \& Deliberato, D. (2012). Tecnologia assistiva para a criança com paralisia cerebral na escola: Identificação das necessidades. Revista Brasileira de Educação Especial, 18, 71 92. http://dx.doi.org/10.1590/S1413-65382012000100006

Sameshima, F. S. (2011). Capacitação de Professores no contexto de Sistemas de Comunicação Suplementar e Alternativa. Tese (Doutorado) - Faculdade de Filosofia e Ciências, Universidade Estadual Paulista, Marília, 2011.

Sameshima, F. S. (2006). Habilidades expressivas de um grupo de alunos não-falantes durante atividades de jogos. Dissertação (Mestrado em Educação) - Faculdade de Filosofia e Ciências, Universidade Estadual Paulista, Marília.

Swengel, E., \& Marquette, D. (1997) Service delivery in AAC. In S. L. Glennen, D. C. De Coste (Eds.), The handbook of argumentative and alternative communication (pp.149-192). San Diego: Singular.

Schirmer, C. R. (2011). A comunicação alternativa na escola: Ensino, pesquisa e prática. In L. R. Nunes, M. Pelosi, \& C. Walter. (Eds.), Compartilhando experiências: Ampliando a comunicação alternativa (pp. 183-196). Marília: ABPEE.

Schirmer, C. R., \& Nunes, L. R. (2011). Introdução à comunicação alternative em classes comuns de ensino. In L. R. Nunes, P. L. Quiterio, C. C. Walter, C. R. Schirmer, \& P. Braun. (Eds.), Comunicar é preciso: Em busca das melhores práticas na educação do aluno com deficiência (pp. 81-91). Marília: ABPEE.

Soto, G., \& Von Tetzchner, S. (2003). Augmentative and alternative communication development through participation in socio-cultural activities in shared educational settings. In S. von Tetzchner \& N. Grove (Eds.), Augmentative and alternative communication: Developmental issues (pp. 287-299). London, UK: Whurr.

Triviños, A. N. S. (1992). Introdução à pesquisa em ciências sociais: A pesquisa qualitativa em educação. 3 ed. São Paulo: Atlas.

Von Tetzchner, S. (2009). Suporte ao desenvolvimento da comunicação suplementar e alternativa. In D. Deliberato, M. J. Gonçalves, \& E. C. Macedo (Orgs.), Comunicaşão alternativa: Teoria, prática, tecnologias e pesquisa (pp. 14-27). São Paulo: Memnon.

Von Teztchner, S., Brekke, K.M., Sjothun, B., \& Grindheim, E. (2005). Inclusão de crianças em educação pré-escolar regular utilizando comunicação suplementar e alternativa. Revista Brasileira de Educação Especial, 11(2), 151-184. 
Von Tetzchner, S., \& Grove, N. (2003). The development of alternative languages forms. In Von S. Tetzchner \& N. Grove (Ed.), Augmentative and alternative communication: Developmental issues (pp. 1-27). London: Whurr.

Wise, P. H. (2012). Emerging technologies and their impact on disability. The Future of Children, 22, 169-191. http://dx.doi.org/10.1353/foc.2012.0002 


\section{Sobre o Autores}

\section{Débora Deliberato}

Professor Adjunto do Departamento de Educação Especial da Unesp de Marília delibera@marilia.unesp.br

Livre-docente na área da Comunicação Alternativa pela Faculdade de Filosofia e Ciências da UNESP/Marília, doutorado em Ciências Médicas pela Universidade Estadual de Campinas (2000), mestrado em Letras - Semiótica e Lingüística Geral pela Universidade de São Paulo (1993). Graduação em Fonoaudiologia pela Universidade Federal de São Paulo - EPM (1985). Docente Adjunto do Departamento de Educação Especial e do Programa de Pós-Graduação em Educação da Faculdade de Filosofia e Ciências do Campus de Marília - Universidade Estadual Paulista Júlio de Mesquita Filho. Tem experiência na área de Fonoaudiologia, com ênfase na Educação Especial, atuando principalmente nos seguintes temas: comunicação suplementar e alternativa, educação especial, formação de profissionais da saúde e da educação no processo inclusivo do deficiente. Tem vários livros e artigos publicados na área da Educação Especial, Comunicação Suplementar e Alternativa. É pesquisadora do CNPq.

\section{Leila Regina d'Oliveira de Paula Nunes}

Professora titular em Educação Especial do Programa de Pós Graduação em Educação e da Faculdade de Educação - Universidade do Estado do Rio de Janeiro leilareginanunes@terra.com.br Possui Bacharelado em Psicologia e Formação de Psicólogo pela Universidade Federal do Rio de Janeiro (1970), mestrado em Special Education na George Peabody College, USA (1977) e doutorado (Ph D) em Special Education - Vanderbilt University (1985). Foi docente da Universidade Federal de S. Carlos e da Universidade Federal do Rio de Janeiro. É bolsista de produtividade em pesquisa do CNPq e Cientista do Nosso Estado pela FAPERJ. Tem experiência em Educação e Psicologia, atuando em áreas como desenvolvimento humano, linguagem e comunicação, interação social, comunicação alternativa, educação de pessoas com deficiência e metodologia experimental de pesquisa. Coordena o Laboratório de Tecnologia Assistiva e Comunicação Alternativa da Faculdade de Educação da UERJ. É sócia da International Society for Augmentative and Alternative Communication e sócia emérita da Associação Brasileira de Pesquisadores em Educação Especial. Coordenou mais de 15 projetos de pesquisa financiados pelo CNPq, CAPES, FAPESP e FAPERJ e orientou quase 50 teses e dissertações. É revisora de periódicos qualificados e autora de vários trabalhos científicos publicados em periódicos qualificados e em diversos livros. Foi organizadora dos seguintes livros: Pesquisa em Educação Especial na Pós-Graduação, Coletâneas da ANPEPP: Prevenção e Intervenção em Educação Especial, Favorecendo o desenvolvimento da comunicação em crianças e jovens com necessidades educacionais especiais, Um retrato da comunicaşão alternativa no Brasil: Relatos de pesquisas e experiências, Comunicar é Preciso: em busca das melhores práticas na educação do aluno com deficiência, Compartilhando experiências: Ampliando a comunicação alternativa, Ensaios sobre autismo e deficiência múltipla e Novas trilhas no modo de faz̧er pesquisa em Educą̧ão Especial. 


\section{Sobre as Editoras Convidadas}

\section{Márcia Denise Pletsch}

Professora do Programa de Pós-Graduação em Educação, Contextos Contemporâneos e Demandas Populares (PPGEduc) na linha de pesquisa Estudos Contemporâneos e Práticas Educativas e do Departamento Educação e Sociedade da Universidade Federal Rural do Rio de janeiro. marciadenisepletsch@gmail.com

A autora é pesquisadora na área de Educação Especial, atuando na formação de professores e de novos pesquisadores. É líder do Grupo de Pesquisa (CNPq) Observatório de Educação Especial e inclusão escolar: práticas curriculares e processos de ensino e aprendizagem e, por meio de convênio interinstitucional entre a UFRRJ e a Universidade do Estado do Rio de Janeiro (UERJ), também é líder do grupo de pesquisa Inclusão e aprendizagem de alunos com necessidades educacionais especiais: práticas pedagógicas, cultura escolar e aspectos psicossociais. Atualmente, coordena o Programa Observatório da Educação da CAPES com projeto de pesquisa em rede na área de deficiência intelectual envolvendo a Universidade Estadual de Santa Catarina (UDESC), Universidade do Vale do Itajaí (UNIVALI); e coordena também pesquisas financiadas pela FAPERJ na área de deficiência múltipla. É autora do livro "Repensando a inclusão escolar: diretrizes políticas, práticas curriculares e deficiência intelectual" e, em colaboração com Rosana Glat, do livro "Inclusão escolar de alunos com necessidades especiais". Organizou em parceria com outros pesquisadores, entre outros, os livros "Estratégias educacionais diferenciadas para alunos com necessidades especiais" e "Educação Especial e inclusão escolar: reflexões sobre o fazer pedagógico". Tem mais de vinte artigos publicados em revistas científicas nacionais e internacionais.

\section{Geovana Mendonça Lunardi Mendes}

Professora do Programa de Pós-Graduação em Educação e do Departamento de Pedagogia da Universidade do Estado de Santa Catarina (PGE-UDESC).

geolunardi@gmail.com

A autora é pesquisadora na área de Educação Especial e dos Estudos Curriculares. Realizou PósDoutorado na Argentina e nos Estados Unidos da América, na área de Currículo e Novas Tecnologias, na Universidad de San Andres em Buenos Aires e em Ashland University, em Ohio. É pesquisadora coordenadora de diferentes projetos de investigação e participa como pesquisadora convidada em projetos de pesquisa nacionais e internacionais. Suas pesquisas e produções têm sido voltadas para área de Currículo e práticas escolares, em especial, as questões relativas as mudanças, novas tecnologias e inovações curriculares no espaço escolar, e também as práticas curriculares voltadas a inclusão de sujeitos com deficiência. Atualmente é a Coordenadora Nacional do Consórcio "Educação e Diversidade" do programa CAPES. FIPSE de Cooperação Internacional, envolvendo a Universidade Federal Rural do Rio de Janeiro, no Brasil e Georgetown College, Ashland University e Brighman Young University nos Estados Unidos e também do Projeto de Pesquisa: Aulas conectadas: mudanças curriculares e aprendizagem colaborativa nas escolas do PROUCA em Santa Catarina, com financiamento do CNPq e do Projeto Observatório de Práticas Escolares com financiamento da FAPESC. É coordenadora do Programa de Pós-graduação em Educação, Mestrado e Doutorado, da FAED, UDESC. Coordena o Observatório da Educação: Tablets, Computadores e Laptops, aprovado no Edital OBEDUC/CAPES. Entre suas atuais produções podem ser destacadas o livro intitulado "Objetos Pedagógicos: uma experiência inclusive em oficinas de Artes", em parceria com mais duas autoras e a organização do Livro "Deficiência e Escolarização: novas perspectivas de analise", hoje na segunda edição. É autora de inúmeros capítulos e artigos publicados em periódicos. 
DOSSIÊ
$\begin{gathered}\text { Educação Especial: Diferenças, Currículo e Processos de Ensino e } \\ \text { Aprendizagem II }\end{gathered}$
arquivos analíticos de políticas educativas
Volume 23 Número 34
16 de março de 2015

\begin{abstract}
(c)
SORERIGHIS RESERVED O Copyright e retido pelo/a o autor/a (ou primeiro co-autor) que outorga o direito da primeira publicação à revista Arquivos Analíticos de Políticas Educativas. Más informação da licença de Creative Commons encontram-se em http://creativecommons.org/licenses/by-nc-nd/2.5. Qualquer outro uso deve ser aprovado em conjunto pelo/s autor/es e por AAPE/EPAA. AAPE/EPAA é publicada por Mary Lou Fulton Institute Teachers College da Arizona State University. Os textos publicados em AAPE são indexados por CIRC (Clasificación Integrada de Revistas Científicas, Espanha) DIALNET (Espanha),Directory of Open Access Journals, Education Full Text (H.W. Wilson), EBSCO Education Research Complete, , ERIC, , QUALIS A2 (Brasil), SCImago Journal Rank; SCOPUS, SOCOLAR (China). Contribua com comentários e sugestões a http://epaa.info/wordpress/ ou para Gustavo E. Fischman fischman@,asu.edu.
\end{abstract}

Curta a nossa comunidade EPAA's Facebook https://www.facebook.com/EPAAAAPE e Twitter feed@epaa_aape. 


\section{arquivos analíticos de políticas educativas conselho editorial}

Editor: Gustavo E. Fischman (Arizona State University) Editores Associados: Rosa Maria Bueno Fisher e Luis A. Gandin

(Universidade Federal do Rio Grande do Sul)

Dalila Andrade de Oliveira Universidade Federal de Minas Gerais, Brasil

Paulo Carrano Universidade Federal Fluminense, Brasil

Alicia Maria Catalano de Bonamino Pontificia Universidade Católica-Rio, Brasil

Fabiana de Amorim Marcello Universidade Luterana do Brasil, Canoas, Brasil

Alexandre Fernandez Vaz Universidade Federal de Santa Catarina, Brasil

Gaudêncio Frigotto Universidade do Estado do Rio de Janeiro, Brasil

Alfredo M Gomes Universidade Federal de Pernambuco, Brasil

Petronilha Beatriz Gonçalves e Silva Universidade Federal de São Carlos, Brasil

Nadja Herman Pontificia Universidade Católica -Rio Grande do Sul, Brasil

José Machado Pais Instituto de Ciências Sociais da Universidade de Lisboa, Portugal

Wenceslao Machado de Oliveira Jr. Universidade Estadual de Campinas, Brasil
Jefferson Mainardes Universidade Estadual de Ponta Grossa, Brasil

Luciano Mendes de Faria Filho Universidade Federal de Minas Gerais, Brasil

Lia Raquel Moreira Oliveira Universidade do Minho, Portugal

Belmira Oliveira Bueno Universidade de São Paulo, Brasil

António Teodoro Universidade Lusófona, Portugal

Pia L. Wong California State University Sacramento, U.S.A

Sandra Regina Sales Universidade Federal Rural do Rio de Janeiro, Brasil

Elba Siqueira Sá Barreto Fundação Carlos Chagas, Brasil

Manuela Terrasêca Universidade do Porto, Portugal

Robert Verhine Universidade Federal da Bahia, Brasil

Antônio A. S. Zuin Universidade Federal de São Carlos, Brasil 


\section{education policy analysis archives editorial board}

Editor Gustavo E. Fischman (Arizona State University)

Associate Editors: Audrey Amrein-Beardsley (Arizona State University), Rick Mintrop, (University of California, Jeanne M. Powers (Arizona State University)

Jessica Allen University of Colorado, Boulder

Gary Anderson New York University

Michael W. Apple University of Wisconsin, Madison Angela Arzubiaga Arizona State University

David C. Berliner Arizona State University

Robert Bickel Marshall University

Henry Braun Boston College

Eric Camburn University of Wisconsin, Madison

Wendy C. Chi* University of Colorado, Boulder

Casey Cobb University of Connecticut

Arnold Danzig Arizona State University

Antonia Darder University of Illinois, UrbanaChampaign

Linda Darling-Hammond Stanford University

Chad d'Entremont Strategies for Children

John Diamond Harvard University

Tara Donahue Learning Point Associates

Sherman Dorn University of South Florida

Christopher Joseph Frey Bowling Green State University

Melissa Lynn Freeman* Adams State College

Amy Garrett Dikkers University of Minnesota

Gene V Glass Arizona State University

Ronald Glass University of California, Santa Cruz

Harvey Goldstein Bristol University

Jacob P. K. Gross Indiana University

Eric M. Haas WestEd

Kimberly Joy Howard* University of Southern California

Aimee Howley Ohio University

Craig Howley Ohio University

Steve Klees University of Maryland

Jaekyung Lee SUNY Buffalo
Christopher Lubienski University of Illinois, UrbanaChampaign

Sarah Lubienski University of Illinois, UrbanaChampaign

Samuel R. Lucas University of California, Berkeley

Maria Martinez-Coslo University of Texas, Arlington

William Mathis University of Colorado, Boulder

Tristan McCowan Institute of Education, London

Heinrich Mintrop University of California, Berkeley

Michele S. Moses University of Colorado, Boulder

Julianne Moss University of Melbourne

Sharon Nichols University of Texas, San Antonio

Noga O'Connor University of Iowa

João Paraskveva University of Massachusetts, Dartmouth

Laurence Parker University of Illinois, UrbanaChampaign

Susan L. Robertson Bristol University

John Rogers University of California, Los Angeles

A. G. Rud Purdue University

Felicia C. Sanders The Pennsylvania State University

Janelle Scott University of California, Berkeley

Kimberly Scott Arizona State University

Dorothy Shipps Baruch College/CUNY

Maria Teresa Tatto Michigan State University

Larisa Warhol University of Connecticut

Cally Waite Social Science Research Council

John Weathers University of Colorado, Colorado Springs

Kevin Welner University of Colorado, Boulder

Ed Wiley University of Colorado, Boulder

Terrence G. Wiley Arizona State University

John Willinsky Stanford University

Kyo Yamashiro University of California, Los Angeles

* Members of the New Scholars Board 


\section{archivos analíticos de políticas educativas consejo editorial}

Editor: Gustavo E. Fischman (Arizona State University)

Editores. Asociados Alejandro Canales (UNAM) y Jesús Romero Morante (Universidad de Cantabria)

Armando Alcántara Santuario Instituto de Investigaciones sobre la Universidad y la Educación, UNAM México

Claudio Almonacid Universidad Metropolitana de Ciencias de la Educación, Chile

Pilar Arnaiz Sánchez Universidad de Murcia, España

Xavier Besalú Costa Universitat de Girona, España

Jose Joaquin Brunner Universidad Diego Portales, Chile

Damián Canales Sánchez Instituto Nacional para la Evaluación de la Educación, México

María Caridad García Universidad Católica del Norte, Chile

Raimundo Cuesta Fernández IES Fray Luis de León, España

Marco Antonio Delgado Fuentes Universidad Iberoamericana, México

Inés Dussel FLACSO, Argentina

Rafael Feito Alonso Universidad Complutense de Madrid, España

Pedro Flores Crespo Universidad Iberoamericana, México
Fanni Muñoz Pontificia Universidad Católica de Perú

Imanol Ordorika Instituto de Investigaciones Economicas - UNAM, México

Maria Cristina Parra Sandoval Universidad de Zulia, Venezuela

Miguel A. Pereyra Universidad de Granada, España

Monica Pini Universidad Nacional de San Martín, Argentina

Paula Razquin UNESCO, Francia

Ignacio Rivas Flores Universidad de Málaga, España

Daniel Schugurensky Arizona State University

Orlando Pulido Chaves Universidad Pedagógica Nacional, Colombia

José Gregorio Rodríguez Universidad Nacional de Colombia

Miriam Rodríguez Vargas Universidad Autónoma de Tamaulipas, México

Mario Rueda Beltrán Instituto de Investigaciones sobre la Universidad y la Educación, UNAM México 
Verónica García Martínez Universidad Juárez Autónoma de Tabasco, México

Francisco F. García Pérez Universidad de Sevilla, España

Edna Luna Serrano Universidad Autónoma de Baja California, México

Alma Maldonado Departamento de Investigaciones Educativas, Centro de Investigación y de Estudios Avanzados, México

Alejandro Márquez Jiménez Instituto de Investigaciones sobre la Universidad y la Educación, UNAM México

José Felipe Martínez Fernández University of California Los Angeles, USA
José Luis San Fabián Maroto Universidad de Oviedo, España

Yengny Marisol Silva Laya Universidad Iberoamericana, México

Aida Terrón Bañuelos Universidad de Oviedo, España

Jurjo Torres Santomé Universidad de la Coruña, España

Antoni Verger Planells University of Amsterdam, Holanda

Mario Yapu Universidad Para la Investigación Estratégica, Bolivia 